\title{
The Skeletal Muscle Impedancemetric Characteristics as a Marker for Detection of Functional State of Organism
}

\author{
Anush Deghoyan, ${ }^{1}$ Robert Simonyan, ${ }^{1}$ Howard Wachtel, ${ }^{2}$ and Sinerik Ayrapetyan ${ }^{1}$ \\ ${ }^{1}$ Department of Biomedical Engineering, UNESCO Chair-Life Sciences International Postgraduate Educational Center, \\ 31 Acharyan Street, 0040 Yerevan, Armenia \\ ${ }^{2}$ Department of ECE, University of Colorado Boulder, 80309-0425 Colorado, USA
}

Correspondence should be addressed to Sinerik Ayrapetyan; info@biophys.am

Received 12 February 2013; Accepted 6 March 2013

Academic Editors: S. Dasdag and M. P. Ponomarenko

Copyright (C) 2013 Anush Deghoyan et al. This is an open access article distributed under the Creative Commons Attribution License, which permits unrestricted use, distribution, and reproduction in any medium, provided the original work is properly cited.

Previously it has been shown that cell hydration is a universal and extrasensitive marker for different environmental mediums and functional state of tissue and organism. The comparative study of cell hydration of different organs (brain cortex, liver, and skeletal muscle) at various experimental conditions (microstress, pathology, and different poisons) was realized. It was shown that among tissues of different organs muscle hydration is more sensitive to any change of functional state of organism and environmental medium. The study of correlation between tissue muscle hydration and double-frequency measurement impedance method indicated that the differences between muscle reactive conductivity measured at high frequency (HF) and low frequency (LF) $\left(\Delta G_{\text {reactive }}\right)$ could be an adequate marker for detection of muscle hydration. The animal poisoning, stress, and pathologyinduced tissue hydration were accompanied by increase in $\Delta G_{\text {reactive }}$. The observed close correlation between time-dependent tissue hydration and $\Delta G_{\text {reactive }}$ in different environmental mediums can be a marker for detection of postmortal period as well as for characterizing environmental medium of the corpse.

\section{Introduction}

At present when technical progress brings the humanity to ecological catastrophe, the adequate detection of environmental pollution from the point of public health has become one of the problems of modern life sciences. The main barrier to solve this problem is that the biological effect of physical and chemical signals on organism cannot be detected only by using their physical parameters because their effect depends on environmental, chemical, and physical characteristics, as well as on functional state of organism. Therefore, only the biological marker of cell and organism could serve as adequate impact of environmental factors on organism. At present it is well established that metabolic controlling of cell hydration determining its functional activity is a universal and extrasensitive parameter for physical and chemical factors [1-3]. The existence of water-transporting protein channels in membrane makes the cell volume extremely variable to osmotic gradients on membrane [4]. However, which of tissues is more sensitive to environmental and functional state changing and could serve as a marker for detection of functional state of organism is not clear yet. It was suggested that the elaboration method of express detection of tissue hydration could serve as a novel diagnostic method for estimation of functional state of organism as well as for detection of postmortal period. Therefore, the following questions served as a subject for the present work:

(1) to elucidate the hydration of which tissue is more sensitive to functional state of organism,

(2) to develop impedancemetric method for express detection of tissue hydration,

(3) to use impedancemetric method for detection of postmortal period of organism and the environmental medium of corpse. 


\section{Materials and Methods}

All procedures performed on animals were carried out following the protocols approved by Animal Care and Use Committee of Life Sciences International Postgraduate Educational Center (Yerevan, Armenia).

2.1. Animals. Experiments were performed on adult male Wistar rats (100-120 g). The animals were purchased from the Animal Resources Centre at the Life Sciences International Postgraduate Educational Center (LSIPEC, Yerevan, Armenia). The animals were kept in a specific pathogen-free animal room under optimum conditions of $12 \mathrm{~h}$ light/dark cycle and $22-28^{\circ} \mathrm{C}$ and received sterilized commercial diet and water $a d$ libitum.

2.2. Chemicals. Tyrode's physiological solution (PS) for rats' experiments, containing (in $\mathrm{mM}$ ) $137 \mathrm{NaCl}$, $5.4 \mathrm{KCl}, 1.8 \mathrm{CaCl}_{2}, 1.05 \mathrm{MgCl}_{2}, 5 \mathrm{C}_{6} \mathrm{H}_{12} \mathrm{O}_{6}, 11.9 \mathrm{NaHCO}_{3}$, $0.42 \mathrm{NaH}_{2} \mathrm{PO}_{4}$, was used and adjusted to $\mathrm{pH} 7.4$ with $\mathrm{NaOH}$; distillated water (DW) was used. All chemicals were obtained from "Medisar" Industrial Chemical Importation Company (Yerevan, Armenia). The $10^{-6} \mathrm{M}$ ouabain (PerkinElmer, Boston, MA, USA) prepared on the basis of the same stock physiological solution for rats' experiments was also used. Anticancer activity of cisPt was studied on the model of transplantable rat tumor (sarcoma-180, Crooker's sarcoma). The rats were intraperitoneally injected with cisplatin $(0.5 \mathrm{~mL}$ per rat) (cisPt) (Cisplatin Ebeve, Austria) with $0.1 \mathrm{mg} / \mathrm{mL}$ concentration.

2.3. Tissue Preparation. It is well known that anesthetics with different chemical and pharmacological profiles [5-7] significantly affect metabolic processes that play an important role in regulation of cell volume $[8,9]$. Therefore, in present experiments, the animals were sharply immobilized by freezing method (dipping their noses into liquid nitrogen for 3-4s) [10]. After such procedure, the full absence of somatic reflexes on extrastimuli was recorded. Investigated tissues (heart muscle, skeletal muscle, lung, liver, spleen, and kidney) were isolated and dissected into the samples weighing from 50 to $70 \mathrm{mg}$ (number of samples was 10 for each tissue). Samples were dried in thermostat (Factory of Medical Equipment, Odessa, Ukraine) during $24 \mathrm{~h}$ at $105^{\circ} \mathrm{C}$, and then their dry masses were defined. The quantity of water in $1 \mathrm{~g}$ of d.w. of tissue was counted by the following equation: (w.w. - d.w.)/d.w. (where w.w. is wet weight and d.w. is dry weight) [11].

2.4. Determination of Tissue Impedance. Impedance measurements were taken over a range of low to high frequencies $(14.5$ and $1450 \mathrm{~Hz})$. After freezing, the impedance measurements were immediately taken on animal leg muscle by "Biophys-Expert-1" (LSIPEC, Yerevan, Armenia). The conductivity-measuring device operates according to functional scheme shown in Figure 1: two electrode clamps (1 and 2) for connection to the measuring cell, resistor (3), low-noise amplifier (4), synchronous detector with synchronous filter

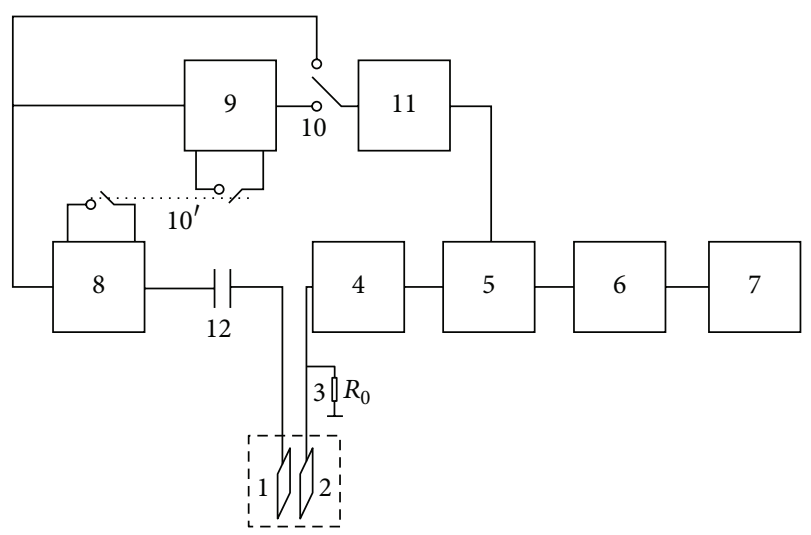

FIGURE 1: The functional scheme of conductivity-measuring device: 1, 2: two electrode clamps, 3: resistor, 4: low-noise amplifier, 5: synchronous detector with synchronous filter, 6: a filter of low frequencies, 7: DC voltmeter, 8: stabilized generator of alternating voltage of sinusoidal form, 9: phase-shifting unit on $90^{\circ}$, 10: switches, 11: voltage transformer from sinusoidal to rectangular, 12: condenser.

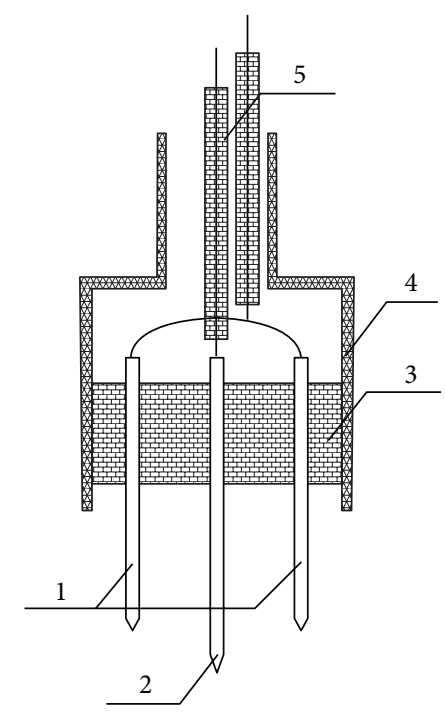

FIGURE 2: The scheme of the measuring cell: 1: radial needles, 2: central needle, 3: dielectric (ebonite), 4: metal coat holder, 5: cable for connection to the device.

(5), a filter of low frequencies (6), DC voltmeter (7), stabilized generator of alternating voltage of sinusoidal form (8), phaseshifting unit on $90^{\circ}$ (9), switches (10 for switching the active and reactive measurements and 10 for switching the high and low frequencies), voltage transformer from sinusoidal to rectangular (11), and condenser (12). Measuring cell consists of the following parts (Figure 2): radial needles (1), central needle (2), dielectric (ebonite) (3), metal coat holder (4), and cable for connection to the device (5).

2.5. Experimental Procedure. In the first series of experiments for defining the more sensitive tissue hydration the changes of hydration of different tissues were performed on 5 animal groups (5 animals in each) in various poisoning conditions 
TABLE 1: Sarcoma-180 and cisPt effects on heart muscle, skeletal muscle, lung, liver, spleen, and kidney tissues.

\begin{tabular}{|c|c|c|c|c|c|}
\hline Organs & Control & Sarcoma-180 & $\Delta \%$ & cisPt & $\Delta \%$ \\
\hline Heart muscle & $2.39 \pm 0.1$ & $3.3 \pm 0.1$ & $\uparrow 38$ & $1.93 \pm 0.15$ & $\downarrow 19.24$ \\
\hline Skeletal muscle & $2.36 \pm 0.23$ & $3.87 \pm 0.21$ & $\uparrow 64$ & $3.08 \pm 0.21$ & $\uparrow 30.5$ \\
\hline Lung & $2.2 \pm 0.15$ & $3.31 \pm 0.03$ & $\uparrow 50.4$ & $1.21 \pm 0.11$ & $\downarrow 45$ \\
\hline Liver & $2.05 \pm 0.12$ & $3.27 \pm 0.15$ & $\uparrow 60$ & $2.27 \pm 0.12$ & $\uparrow 10.73$ \\
\hline Spleen & $2.23 \pm 0.13$ & $2.8 \pm 0.14$ & $\uparrow 25.5$ & $2.13 \pm 0.12$ & $\downarrow 4.48$ \\
\hline Kidney & $2.05 \pm 0.13$ & $3.36 \pm 0.19$ & $\uparrow 64$ & $2.05 \pm 0.12$ & - \\
\hline
\end{tabular}

TABLE 2: The ouabain $10^{-8} \mathrm{M}$ and $10^{-6} \mathrm{M}$ concentrations effect on heart muscle, skeletal muscle, lung, liver, spleen, and kidney tissues.

\begin{tabular}{|c|c|c|c|c|c|}
\hline \multirow{3}{*}{$\begin{array}{l}\text { Healthy } \\
\text { Organ }\end{array}$} & \multicolumn{5}{|c|}{ Tissue hydration (water content $\mathrm{g} / \mathrm{g}$ dry mass) } \\
\hline & \multicolumn{5}{|c|}{ Ouabain concentration $(\mathrm{M})$} \\
\hline & Control & Ouabain $10^{-8} \mathrm{M}$ & $\Delta \%$ & Ouabain $10^{-6} \mathrm{M}$ & $\Delta \%$ \\
\hline Heart muscle & $2.389 \pm 0.1$ & $2.7 \pm 0.26$ & $\uparrow 13.02$ & $2.306 \pm 0.05$ & $\downarrow 3.47$ \\
\hline Skeletal muscle & $2.357 \pm 0.23$ & $3.361 \pm 0.25$ & $\uparrow 42.6$ & $3.421 \pm 0.3$ & $\uparrow 45.14$ \\
\hline Lung & $2.199 \pm 0.15$ & $2.243 \pm 0.06$ & $\uparrow 2.01$ & $2.167 \pm 0.3$ & $\downarrow 1.46$ \\
\hline Liver & $2.054 \pm 0.12$ & $2.547 \pm 0.18$ & $\uparrow 24.01$ & $2.92 \pm 0.17$ & $\uparrow 42.16$ \\
\hline Spleen & $2.225 \pm 0.13$ & $2.444 \pm 0.25$ & $\uparrow 9.84$ & $3.147 \pm 0.3$ & $\uparrow 41.44$ \\
\hline Kidney & $2.05 \pm 0.13$ & $2.878 \pm 0.19$ & $\uparrow 40.32$ & $3.09 \pm 0.15$ & $\uparrow 50.66$ \\
\hline
\end{tabular}

$\left(10^{-6} \mathrm{M}, 10^{-8} \mathrm{M}\right.$ ouabain concentration, and cisPt), pathology (sarcoma-180), and Morris water maze (as stress cause). For estimation of hydration in conditions of osmotic stress the next series of experiments were performed on 3 groups ( 5 animals in each) of animals (intact, PS and, DW injected). After 30 minutes of injection the animals were sharply immobilized by dipping their noses into liquid nitrogen for 3-4 sec [10] and died. The same procedure was done on the intact animal group. After this the leg muscle was prepared and its tissue impedance was measured. Water content in skeletal muscle tissue was determined by tissue-drying method.

For detecting the post-mortal period the animals were kept in different environmental mediums (dry medium, tap water). For each method post-mortal tissue impedance measurements were carried out simultaneously on a group of 5 animals. The measurements on the first day were made hourly and on the second day every 3-hour interval. On remaining days the records were carried out only once a day. This procedure was repeated for each group of rats.

2.6. Statistical Analysis. The Microsoft Excel and Sigmaplot (version 8.02A, NY, USA) were used for data analysis. Significance in comparison with the control group was calculated with Student's paired $t$-test with the following symbols $\left({ }^{*} P<0,05 ;{ }^{* *} P<0,01 ;{ }^{* * *} P<0,001\right)$.

\section{Results}

3.1. Tissue Hydration Dependency on Functional State of Organism. It is known that any cell pathology (including cancer, nerve, cardiovascular diseases, and aging) is a consequence of dysfunction of metabolic controlling of cell hydration $[1,12-$ 14]. As can be seen in Table 1 the sarcoma-180 injection leads to overhydration in different tissues (heart muscle, skeletal muscle, lung, liver, spleen, and kidney). Among them the skeletal (64\%) and kidney muscle hydrations (64\%) are more sensitive. It is known that cisPt is widely used in clinic as an anticancer chemotherapeutic factor. As can be seen from data presented in Table 1 cisPt intraperitoneal injection had also pronounced hydration effect on skeletal muscle (30.5\%) and dehydration effect on lung $(45 \%)$. The fact that $\mathrm{NA}^{+} / \mathrm{K}^{+}$pump has a crucial role in cell hydration and its dysfunction can be considered as a common consequence of any pathology $[1,12-14]$. The effect of ouabain (specific inhibitor for $\mathrm{NA}^{+} / \mathrm{K}^{+}$ pump) on various tissues' hydration was studied. The study of $10^{-6} \mathrm{M}$ ouabain-poisoned animals also indicates that skeletal muscle overhydration (45.14\%) was more essential than that of other tissues. As can be seen in Table 2 the overhydration of muscles takes place also even at low $\left(10^{-8} \mathrm{M}\right)$ ouabain concentration-poisoned animals (42.6\%). The muscle hydration was studied after applying Morris water maze method. As can be seen in Figure 3 again we had skeletal muscle overhydration. Thus, the above-presented data clearly indicate that muscle hydration could be a universal marker for detection of functional state of organism.

3.2. The Comparative Study of Tissue Hydration of Different Organs and Impedance Characteristics of Skeletal Muscle. In order to elaborate the express method for detection of muscle hydration the correlation between muscle hydration and impedance characteristics at double frequencies was studied. Therefore, the study of intraperitoneal injection with PS $(1 \mathrm{~mL})$ and DW $(1 \mathrm{~mL})$ in skeletal muscle as well as the impedance characteristics was performed. As can be seen from Figure 4 in all two cases (PS and DW injection) the hydration increases by $16 \%$ and $49 \%$ in skeletal muscle tissue, correspondingly. The impedance of a biological tissue consists of two components, the active and the reactive resistance. The conductive characteristics of the cell membranes provide the active component, acting as imperfect capacitors 


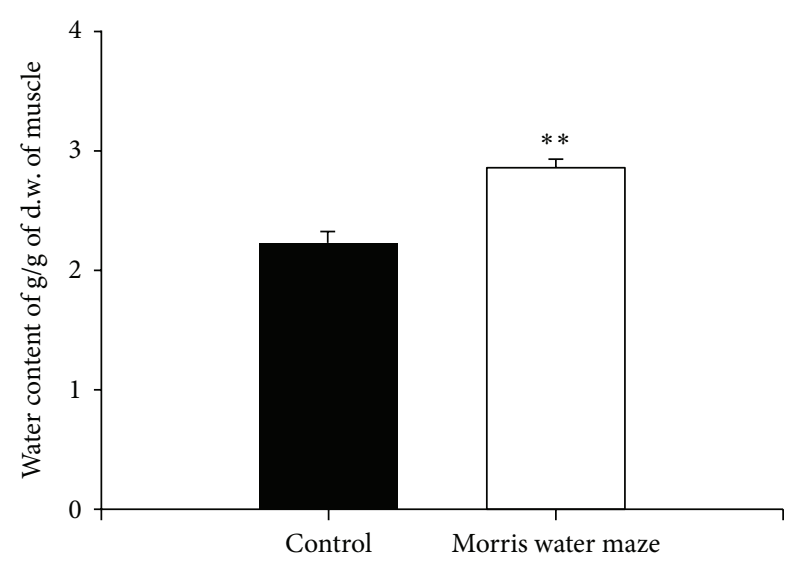

(a)

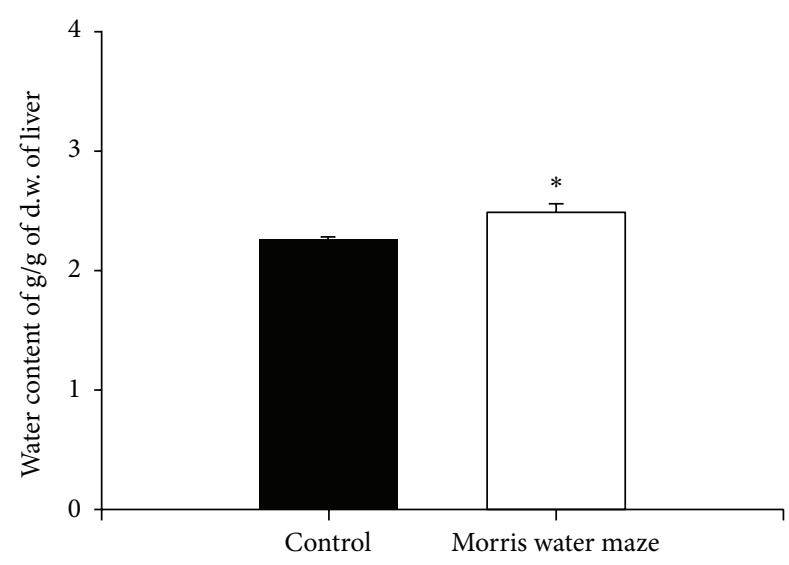

(b)

Figure 3: Morris water maze effect on value water content of skeletal muscle (a) and liver (b) tissues. Black bars indicate the control value of water content in tissues and white bars indicate the experimental data. Error bars indicate SEM. Values were statistically significant (compared to data of control group $\left.{ }^{*} P<0.05,{ }^{* *} P<0.01\right)$.

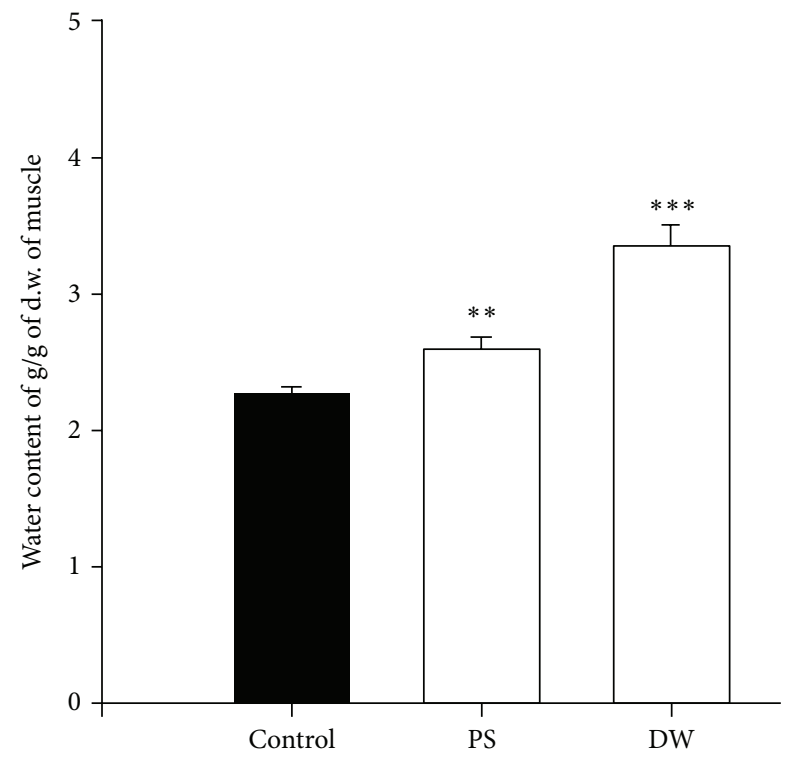

FIGURE 4: PS and DW injections effects on values of skeletal muscle water content. Black bar indicates the control value of water content. White bars indicate the experimental data of injected (PS and DW) animals. Each bar represents the mean of water content from 5 animals. Error bars indicate SEM. Values were statistically significant (compared to data of control group ${ }^{* *} P<0.01,{ }^{* * *} P<0.001$ ).

contributing to a frequency-dependent reactive component. Impedance measurements were made at a range of low to high frequencies $(14.5 \mathrm{~Hz}$ to $1450 \mathrm{~Hz})$. This allows to predict on extracellular (measuring at low frequencies) and intracellular water volume (measuring at high frequencies) as differences between tissues impedance [15].

In Figure 5 the impedance characteristics changes under influences of PS and DW are shown. As can be seen from Figure 5(a) the active conductivity at HF has no significant changes, while the active conductivity at LF is higher in
PS and lower in DW, compared to control (Figure 5(c)). In case of reactive conductivity at HF we observed the statistics increasing after PS injections (Figure 5(b)). At LF PS injection leads to the decrease of active conductivities and DW leads to the increase in the mentioned components (Figure 5(d)). As in both PS and DW we had cell hydration but in case of DW injection-induced cell swelling is accompanied by decrease of extracellular fluid active conductivity (saline dilution); it was suggested that differences between reactive conductivity at LF and HF could indicate the pure cell hydration in isotonic medium. As it is shown in Figure 6, the difference of reactive conductivity of double frequency is reversed compared to control and DW injection. Thus, the reversion of $\Delta G_{\text {reactive }}$ can serve as a marker for cell overhydration.

3.3. The Time-Dependent Changes of $\Delta G_{\text {reactive }}$ during Postmortal Period of Corpse. In the next series of experiments the animals were kept in different conditions (water and dry medium). Initial $\Delta G_{\text {reactive }}$ was higher in animals which were kept in water medium. There are big differences between time-dependent kinetics of reactive conductivity kept in dry and water mediums. These differences appeared in the first three hours of post-mortal period: in water medium $\Delta G_{\text {reactive }}$ sharply increases during 3 hours, while in dry medium it has very slow decreasing. In water medium slow decreasing of $\Delta G_{\text {reactive }}$ continues till 48 hours and then sharply increases. But in case of dry medium slow decreasing continues till 12 hours then it sharply decreases with highamplitude oscillation (Figure 7). These data clearly indicate that the time-dependent changing of $\Delta G_{\text {reactive }}$ can be used for detection of post-mortal period and characterize the medium in which the corpse was kept.

\section{Discussion}

For more than three decades overhydration of cells has been used as a marker for early detection of carcinogenesis. 


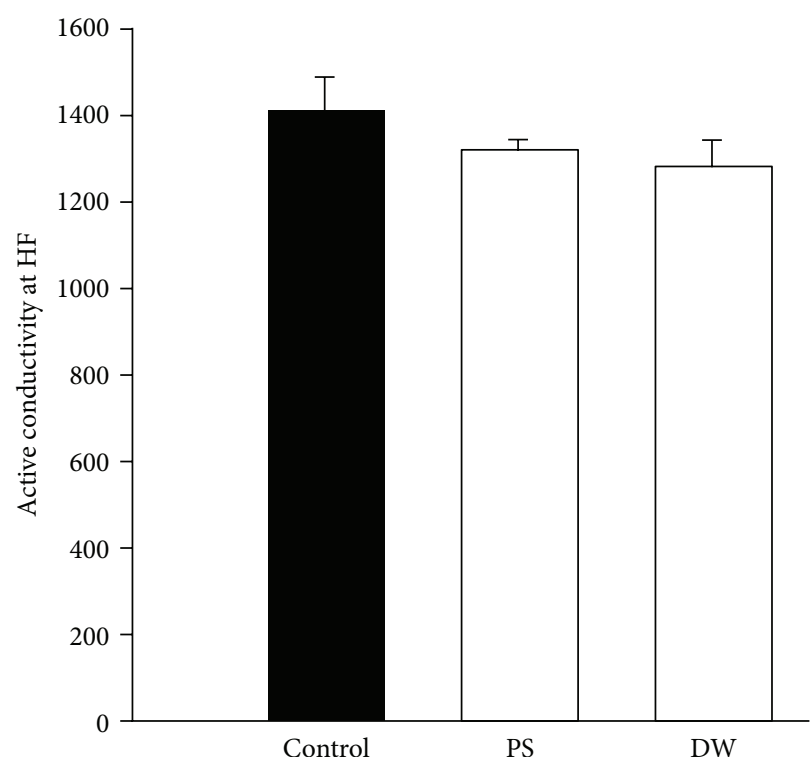

(a)

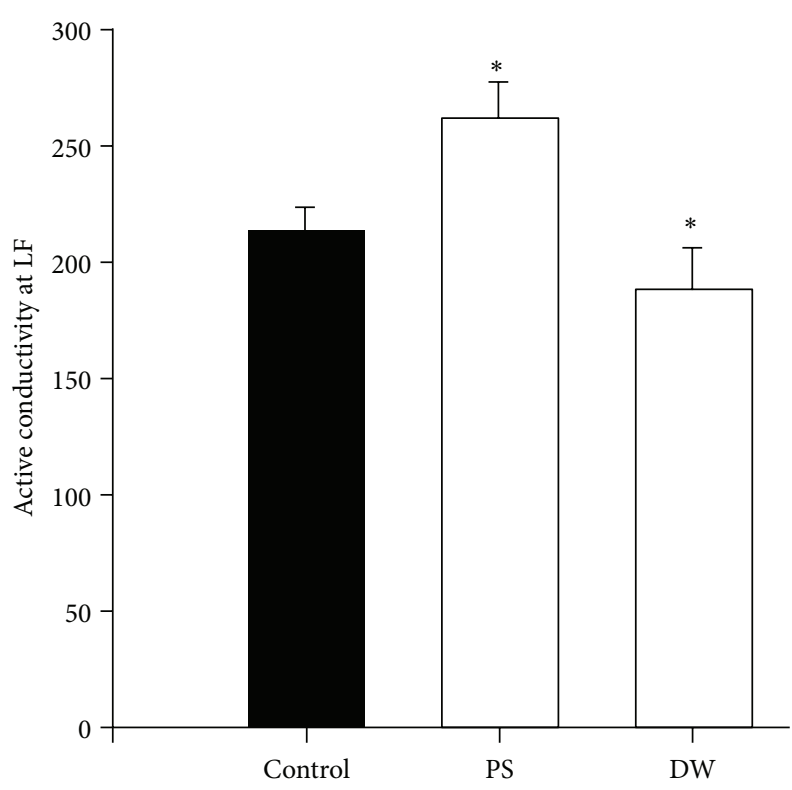

(c)

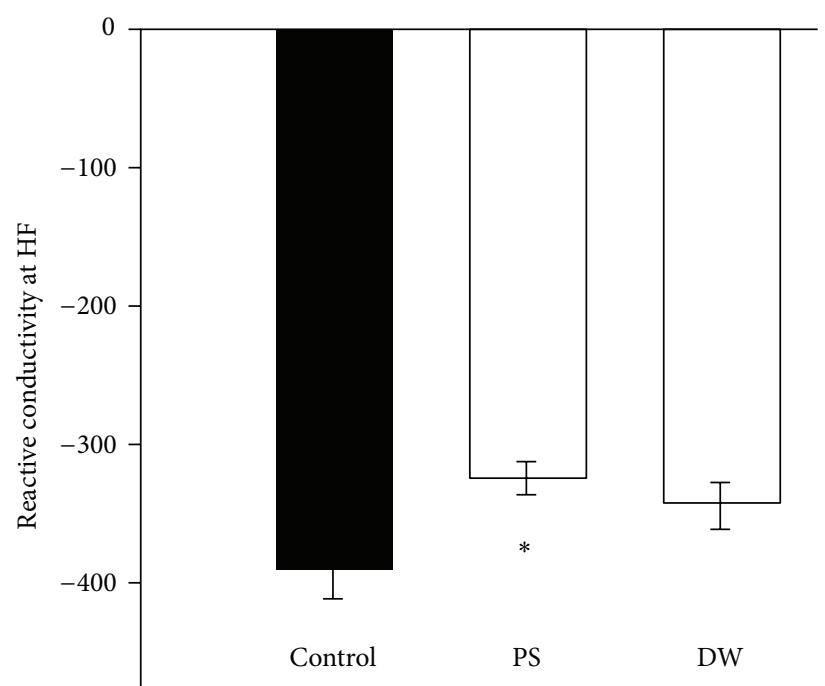

(b)

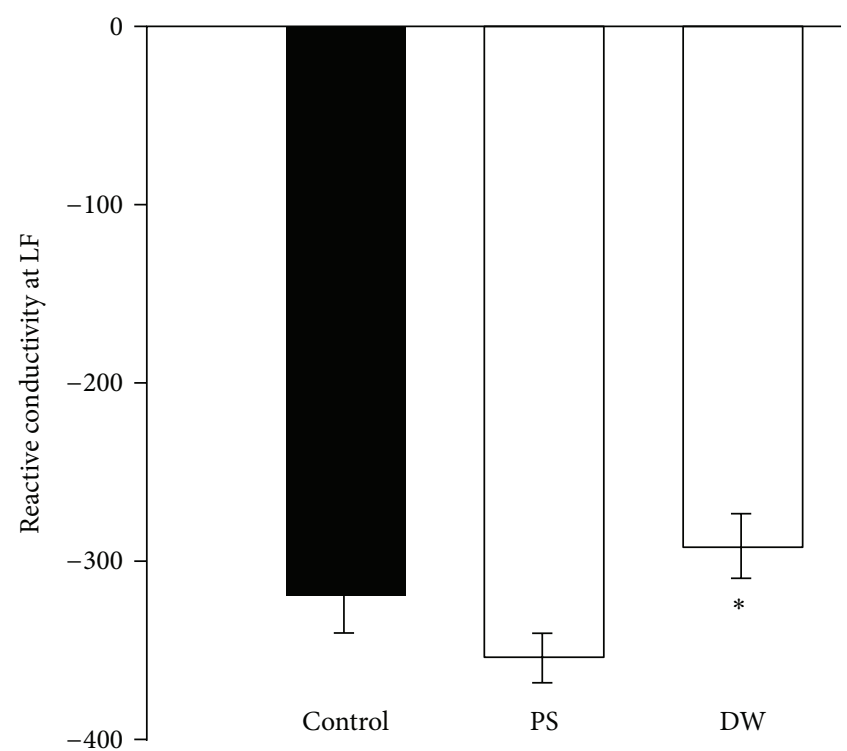

(d)

FIGURE 5: The changes of active (a) and reactive (b) conductivities at high frequency. The changes of active (c) and reactive conductivities (d) at low frequency. Black bars indicate the control value of active and reactive conductivities and white bars indicate experimental data after PS and DW injections. Error bars indicate SEM. Values were statistically significant (compared to data of control group ${ }^{*} P<0.05$ ).

For this purpose nuclear magnetic resonance tomography (NMR) was used. This method is rather expensive and is not available for wide public usage. The data presented in the work indicate that overhydration of cells also takes place in pathology such as sarcoma-180 injection (Table 1). Therefore, cell overhydration can be suggested as a universal diagnostic parameter for cell pathology. Nevertheless, the skeletal muscle hydration was more sensitive compared to other organs. It is interesting to note that overhydration of skeletal muscle was observed also in rats preliminarily injected with anticancer cisPt, while it had strong dehydration effect on lung and heart muscle. The data that $10^{-6} \mathrm{M}$ ouabain-induced skeletal muscle overhydration (45\%) took place in rats preinjected with $10^{-6} \mathrm{M}$ ouabain indicate that cell overhydration is not caused by $\mathrm{Na}^{+} / \mathrm{K}^{+}$pump inhibition (Table 2), while the fact that $10^{-8} \mathrm{M}$ which has no inhibitory effect on $\mathrm{Na}^{+} / \mathrm{K}^{+}$pump also had overhydration effect on muscles can be explained by the dysfunction of intracellular signalling system controlling cell hydration (Table 2) [16, 17]. The obtained data that Morris water maze induced stress 


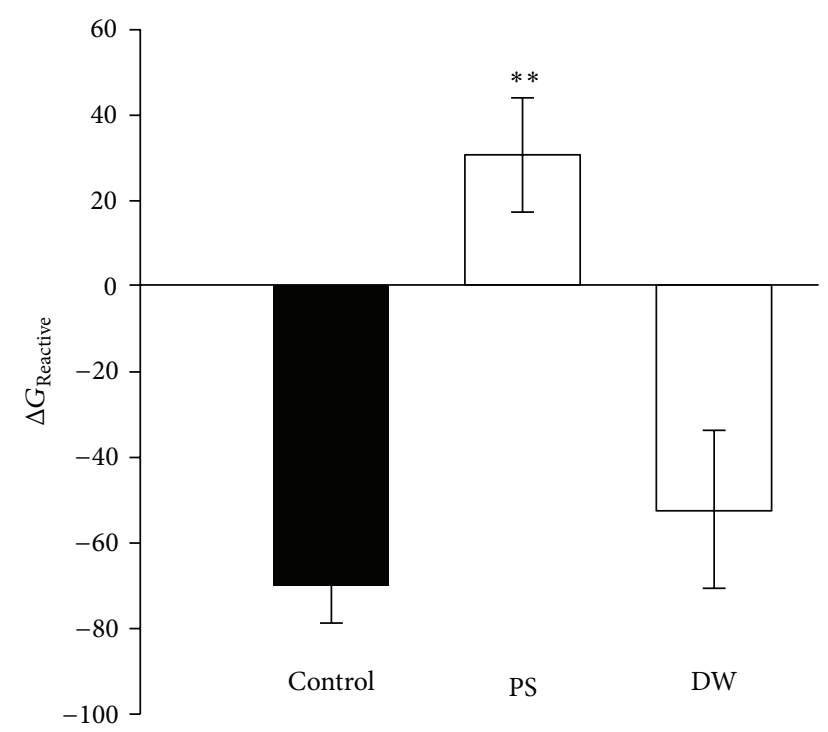

FIgURE 6: The changes of $\Delta G_{\text {reactive }}$ after PS and DW injection. Black bar indicates the control value and white bars indicate experimental data. Error bars indicate SEM. Values were statistically significant (compared to data of control group ${ }^{* *} P<0.01$ ).

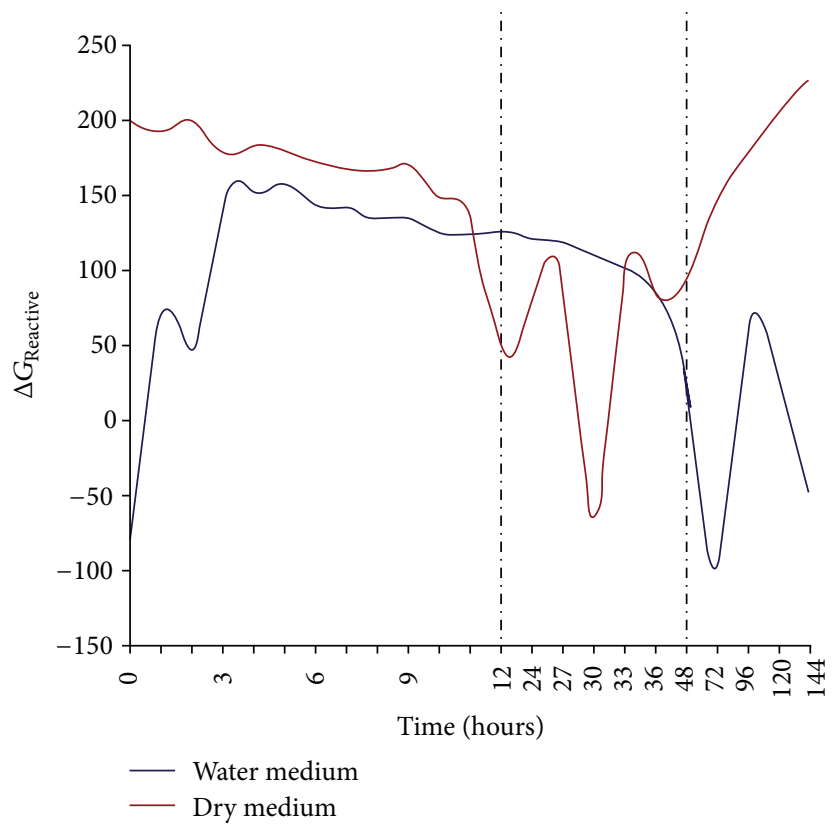

FIgURE 7: The time-dependent changes of $\Delta G_{\text {reactive }}$ of skeletal muscle tissues in water and dry mediums. The red curve indicates the changes of impedance characteristics in dry medium and the blue curve in water medium. Abscissa: the time recordings (from 0 to 144 hours). The measurements on the first day were made hourly and on the second day every 3 -hour interval. On remaining days the records were carried out only once a day. Ordinates: the reactive conductivities change at high and low frequency differences (HFLF) $\left(\Delta G_{\text {reactive }}\right)$. For each curve 5 independent experiments were done. The difference between groups was statistically significant $\left({ }^{*} P<0.05\right)$. which also brings to overhydration confirms the suggestion that skeletal muscle hydration serves as a universal marker for functional state of organism. The impedance measurement method is also used in clinics for diagnostic purposes [18]. Double-frequency method can be used for determination of extracellular and intracellular fluid detection. Obtained data on the close correlation between skeletal muscle hydration and its impedance characteristics at LF and HF indicate that $\Delta G_{\text {reactive }}$ could serve as a sensitive parameter for detection of functional state of organism (Figures 5 and 6). The received data on great differences in time-dependent kinetics of $\Delta G_{\text {reactive }}$ of leg muscle in rats, the corpses of which were in dry and water mediums, allow us to suggest this method for determination of post-mortal period as well as to characterize the medium in which the corpses were kept. Thus, the doublefrequency measurement at HF and LF in skeletal muscle could serve as a universal diagnostic parameter for functional state of organism as well as for estimation of hazardous effect on environmental pollutions.

Thus, obtained data bring us to the following conclusions.

(1) Cell overhydration is a marker for dysfunctional state of organism (pathology, poisoning, and stress).

(2) Skeletal muscle hydration is the most sensitive to functional state of organism compared to other tissues; therefore, its hydration can serve as a marker for detection of functional state of organism.

(3) The double-frequency method can be used for detection of muscle hydration.

(4) The novel method can be recommended for detection of post-mortal period and characterization of the medium in which the corpse was kept.

\section{Conflict of Interests}

The authors have no conflicts of interest.

\section{Acknowledgments}

This work was supported by CRDF Cooperative Grants Program (Award no.- AR-E2-2584-YE-04). The authors express their gratitude to Tatevik Arzumanyan for secretary work.

\section{References}

[1] D. Haussinger, "Regulation of cell function by level of hydration," Naturwissencheften, vol. 83, pp. 264-271, 1996.

[2] F. Lang, M. Föller, K. S. Lang et al., "Ion channels in cell proliferation and apoptotic cell death," Journal of Membrane Biology, vol. 205, no. 3, pp. 147-157, 2005.

[3] S. N. Ayrapetyan, "Cell hydration as a universal marker for detection of environmental pollution," The Environmentalist, vol. 32, no. 2, pp. 210-221, 2012.

[4] P. Agre, A. M. Saboori, A. Asimos, and B. L. Smith, "Purification and partial characterization of the M(r) 30,000 integral membrane protein associated wih the erythrocyte $\mathrm{Rh}(\mathrm{D})$ antigen," The Journal of Biological Chemistry, vol. 262, no. 36, pp. 17497$17503,1987$. 
[5] R. A. Haworth, A. B. Goknur, and H. A. Bertroff, "Inhibition of Na-Ca exchange by general anesthetics," Circulation Research, vol. 65, pp. 1021-1028, 1989.

[6] A. Heqimyan, A. Deghoyan, and S. Ayrapetyan, "Ketamineinduced cell dehydration as a mechanism of its analgesic and anesthetic effects," Journal of International Dental and Medical Research, vol. 4, no. 1, pp. 42-49, 2011.

[7] K. Kmjevic, "Central actions of general anesthetics," in Molecular Mechanisms in General Anesthesia, M. J. Halsey, R. A. Miller, and J. A. Sutton, Eds., pp. 65-68, Churchill Livingstone, Edinburgh, UK, 1974.

[8] N. P. Blaustein and W. J. Lederer, " $\mathrm{Na}^{+} / \mathrm{Ca}^{2+}$ exchange. Its physiological implications," Physiological Reviews, vol. 79, pp. 763854, 1999.

[9] R. Dipolo and L. Beauge, " $\mathrm{Na}^{+} / \mathrm{Ca}^{2+}$ exchanger: influence of metabolic regulation on ion carrier interaction," Physiological Reviews, vol. 86, pp. 155-203, 2006.

[10] R. Takahashi and M. Aprison, "Acetylcholine content of discrete areas of the brain obtained by a near-freezing method," Journal of Neurochemistry, vol. 11, pp. 887-892, 1964.

[11] R. H. Adrian, "The effect of internal and external potassium concentration on the membrane potential of frog muscle," The Journal of Physiology, vol. 133, pp. 631-658, 1956.

[12] F. Lang, "Mechanisms and significance of cell volume regulation," Journal of the American College of Nutrition, vol. 26, no. 5, pp. 613-623, 2007.

[13] A. Heqimyan, L. Narinyan, A. Nikoghosyan, A. Deghoyan, L. Yeganyan, and S. Ayrapetyan, "Age dependency of highaffinity ouabain receptors and their magnetosensitivity," The Environmentalist, vol. 32, pp. 228-235, 2012.

[14] L. Narinyan, G. Ayrapetyan, and S. Ayrapetyan, "Age-dependent magnetosensitivity of heart muscle hydration," Bioelectromagnetics, vol. 33, no. 6, pp. 452-458, 2012.

[15] H. Wachtel, R. Simonyan, H. Stepanyan, and S. Ayrapetyan, "Measurement of changes in tissue impedance as a method for rapidly determining post mortem duration and cause of death," in Proceedings of the ONRG/EOARD/IUPAB Seminar of Mechanisms of Mechanotransduction in Living Cells, Yerevan, Armenia, August 2006.

[16] S. N. Ayrapetyan, M. A. Suleymanyan, A. A. Saghyan, and S. S. Dadalyan, "Autoregulation of the electrogenic sodium pump," Cellular and Molecular Neurobiology, vol. 4, no. 4, pp. 367-383, 1984.

[17] Z. Xie and A. Askari, " $\mathrm{Na}^{+} / \mathrm{K}^{+}$-ATPase as a signal transducer," European Journal of Biochemistry, vol. 269, no. 10, pp. 24342439, 2002.

[18] H. C. Lukaski, P. E. Johnson, W. W. Bolonchuk, and G. I. Lykken, "Assessment of fat-free mass using bioelectrical impedance measurements of the human body," American Journal of Clinical Nutrition, vol. 41, no. 4, pp. 810-817, 1985. 

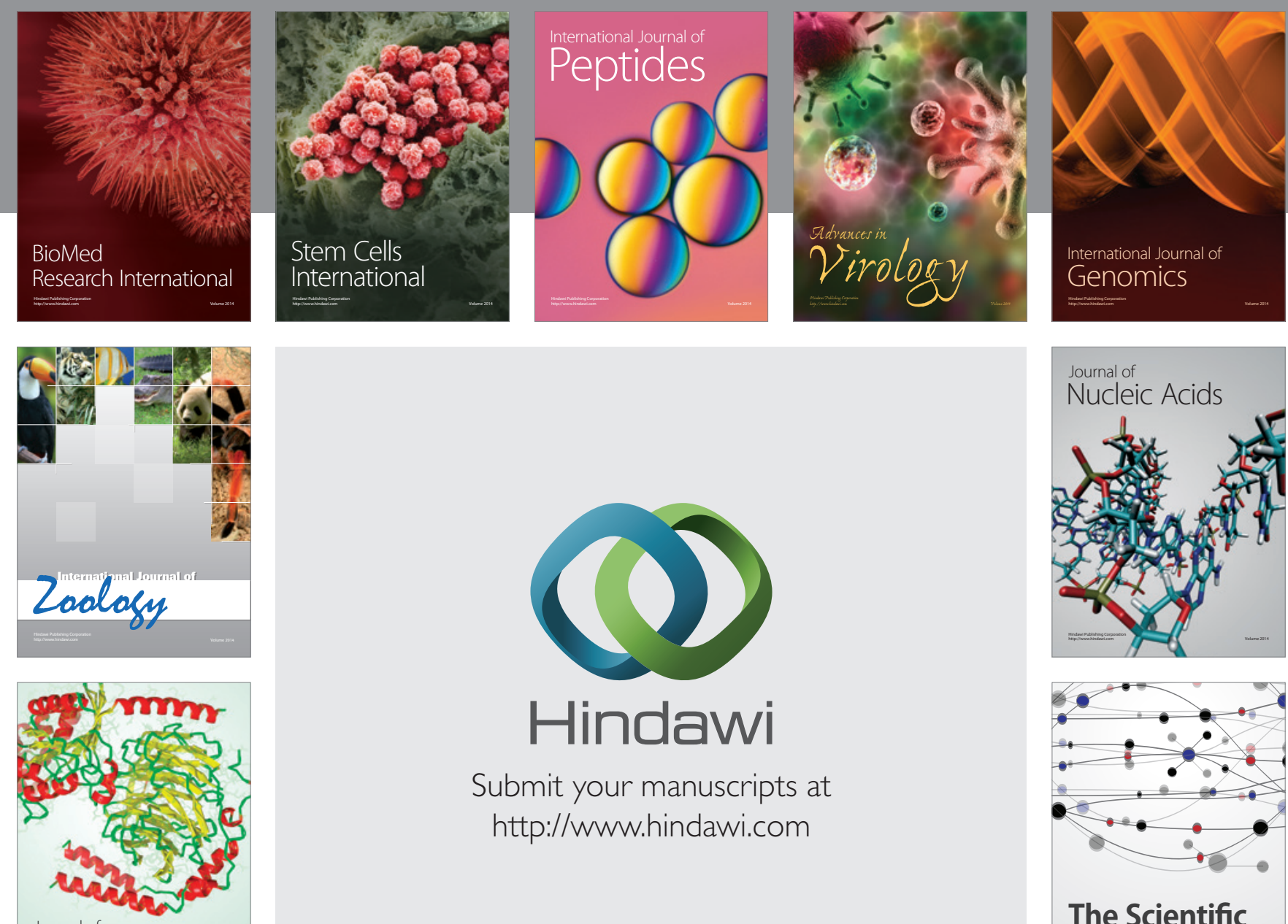

Submit your manuscripts at

http://www.hindawi.com

Journal of
Signal Transduction
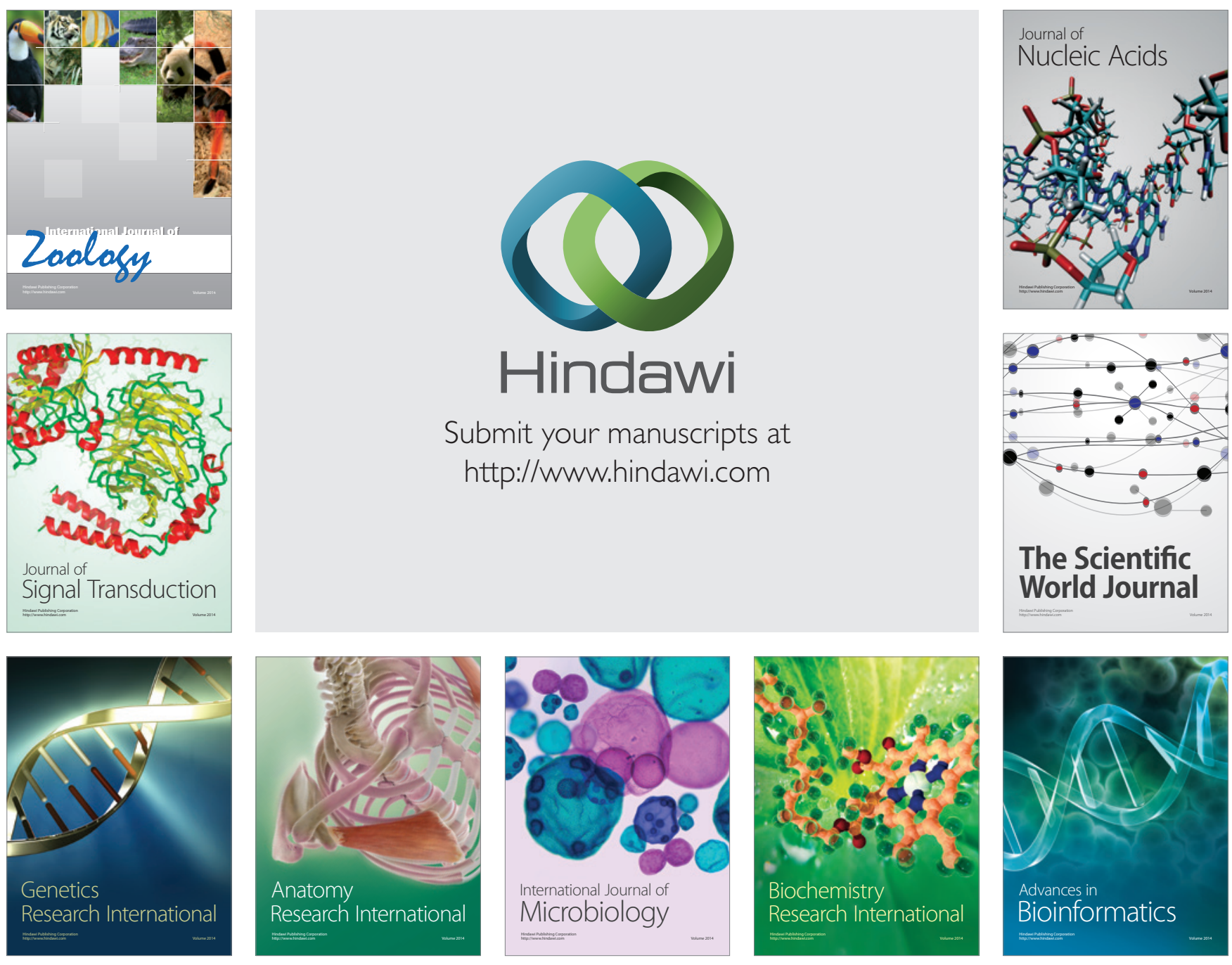

The Scientific World Journal
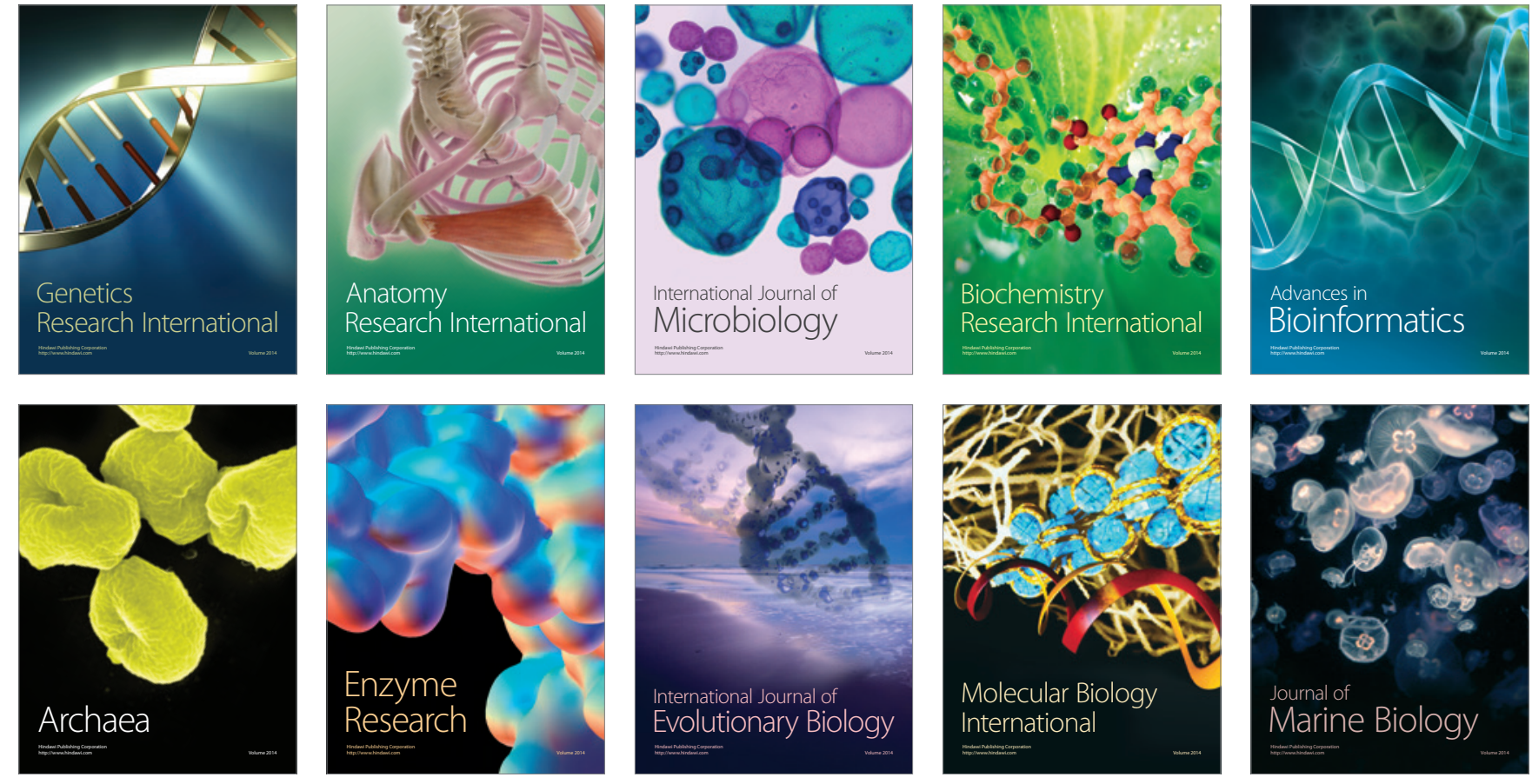